\title{
Legal and Political Competitiveness for Pharmaceuticals
}

\author{
Marcus Oehlrich ${ }^{\mathrm{a}}$ and Arthur Daemmrich ${ }^{\mathrm{b}}$ \\ ${ }^{a}$ Volker Karl Oehlrich - Gesellschaft e.V., Riedstadt, Germany \\ ${ }^{\mathrm{b}}$ University of Kansas Medical Center, Kansas City, KS, USA
}

\section{The contested pharmaceutical industry}

The pharmaceutical industry operates both as an important business sector and a vital contributor to the delivery of health services worldwide. In 2012, the total world market for pharmaceutical products amounted to nearly US $\$ 1$ trillion (see Table 1). Although global in scope, some 60 percent of sales were in North America and Europe, which comprise only 15 percent of the world's population. The industry plays an important economic role in many countries by contributing to national income and employing hundreds of thousands of educated workers. Studies in the United States and Germany have found that for each direct employee, the pharmaceutical industry also generates between 1.6 and 3.5 jobs in supporting industries [7, 9]. While Germany long boasted of its role as the "world's apothecary," firms in Switzerland, France, the United Kingdom, and the United States also have underwritten decades of research into new medicines and brought several thousand new medicines to market since the late 19th century [1].

However, since the early 2000s, a steady decline in global prescription drug sales has accompanied an international deterioration in the underlying conditions critical to pharmaceutical in novation [6]. Troubles can be found also in a declining number of new chemical or biological medicines approved for markets despite a steady rise in research spending [8]. Policy discussions in some countries reveal a shift against industry arguments that high profit margins on current drug sales are necessary to finance research into future pharmaceuticals. Countries across the OECD instead are looking for ways to reduce health spending and national pharmaceutical budgets have been held constant or even reduced. Policies including reference pricing and demands that the industry demonstrate the cost effectiveness of its products are now widespread, especially in Europe [4].

Articles in this special issue of Pharmaceuticals Policy and Law analyse factors governing the legal and competitive environment for the pharmaceutical sector. Key issues are explored across the full pharmaceutical value chain, including drug discovery, development, authorization, and marketing. The articles demonstrate widespread, typically longstanding, tensions between policies that on the one hand 
Table 1

Global PharmaceuticalSales, 2003-2012

\begin{tabular}{lcccccccccc}
\hline & 2003 & 2004 & 2005 & 2006 & 2007 & 2008 & 2009 & 2010 & 2011 & 2012 \\
\hline Total World Market $^{\mathrm{a}}$ & 558 & 601 & 646 & 691 & 740 & 787 & 843 & 889 & 937 & 959 \\
Annual Growth (\%) & 10.2 & 7.8 & 7.4 & 7.1 & 7.0 & 6.4 & 7.1 & 5.5 & 5.3 & 2.4 \\
\hline
\end{tabular}

${ }^{a}$ Constant (2005) US\$, billions. Source: IMS Health, "Top-line market data: Global prescription sales information," www.imshealth.com, accessed December 2014.

support high profits and investments into new drug research by the industry, and on the other hand target pharmaceutical spending through greater use of generics or price controls. Three areas emerge from the collected articles as especially significant to the pharmaceutical business environment: first, health care systems that provide financial incentives for innovation; second, social and legal structures that support innovation; and third, a regulatory environment that enables innovation.

\subsection{Health care systems and incentives for innovation}

As recently as the mid-1980s, few countries had controls on drug prices, and manufacturers held monopoly power over their innovative medicines, limited only by patent terms. Physicians disregarded pharmaceutical costs and prescribed medicines with little, if any, administrative oversight. Supported by patents, pharmaceutical firms were not only able to recoup their research and development (R\&D) costs, but also were rewarded with superior profit margins on invested capital.

But since the 1990s cost reduction efforts have gained momentum and are starting to put significant pressure on the industry. Price levels of branded drugs have come under particular attention. In most countries, the pricing of pharmaceuticals is not only influenced by competitive market forces, but also by national interventions including price or profit controls, budgets, and payment regulations. Pharmacoeconomic studies have, in some countries, been built up as a fourth hurdle (beyond quality, safety, and efficacy) for new drugs by mandating that innovativeness be evaluated against medical utility. The U.K.'s National Institute for Health and Care Excellence (NICE) led this development by defining a clear price for life years gained through medical interventions. Drugs falling below defined thresholds of longevity benefits relative to defined cost parameters have been delayed from entering the U.K. market.

In order to provide incentives for innovation, the reimbursement processes has to be transparent, fair, swift and predictable. Thus several verdicts of the European Court of Justice have called for a common pharmaceutical market. At present, however, a common pharmaceutical market is seriously hampered by 27 different health care systems, driven by their own traditions, legal provisions, and price policies. Increasingly, national pricing and reimbursement policies do not provide rewards for innovative products compared to older medicines.

Health care policy is also economic policy and vice versa. Changes to health policy should be understood as economic decisions concerning industrial research and the 
competitiveness of domestic pharmaceutical companies. Because health policy measures shape the incentives offered to companies for their research, short-term savings may have to be "bought" over the long-term with additional costs for other forms of care or through fewer new medicines for diseases affecting millions of patients.

\subsection{Social and legal structures that support innovation}

In addition to market demand from physicians and patients, other contextual variables are critical for countries seeking to establish or sustain an innovative pharmaceutical sector. Numerous studies have shown the significance of spill over effects, notably the diffusion of specialized knowledge among academic and private sector organizations in biomedical clusters, such as those found in Boston or San Diego [3, 5]. Spillovers include the exchange of ideas through informal meetings, formal workshops and conferences, and the movement of scientists between companies in a specific geography. They are beneficial to innovation because they constitute pathways for the exchange of knowledge outside of the licensing of patented inventions or formal joint ventures.

Legal conditions are also critical to pro-innovation environments. Intellectual property (IP) protections are a frequent topic of controversy for the monopoly market rights they support. At present, some countries are seeking to reduce IP rights in order to generate more competition among pharmaceutical producers. But nations with effective protection of property rights through patents, trademarks, and confidentiality of pharmaceutical registration data have benefitted from the industry's growth. Newer initiatives such as innovation prizes remain linked to legal structures governing the uses of intellectual property. At the same time, some legal policies that protect firms, for example non-compete clauses in employment contracts, may work against the creation of an innovative ecosystem.

\subsection{The regulatory environment and innovation}

The pharmaceutical industry has operated under regulations governing product labelling and requiring pre-market studies for decades. In recent years, controls over animal and human subject research have intensified in nearly all countries. Despite striking consistency in legal mandates for drug quality, safety, and efficacy, significant international variation remains in the interpretation of study results. As a result, firms regularly encounter inconsistent approval decisions around the world. In many cases, sponsors have to carry out clinical trials within a given country before applying for market authorization.

At present, the regulatory context for pharmaceuticals in changing thanks to emergent supranational and international harmonization. Across the European Union, the European Medicines Agency (EMA) has over 15 years' experience in the review and authorization of pharmaceuticals. In addition, the International Conference on Harmonization (ICH) has brought together regulatory officials with industry trade 
associations from the United States, European Union, and Japan for two decades. ICH has achieved global standards for pre-clinical, clinical, and post-market monitoring studies. While a single global drug approval process remains elusive, ICH has reduced or eliminated some of the duplication of in-vitro, animal, and human studies for national regulatory authorities. But despite promoting standards and reciprocal acceptance of clinical trial data, ICH has not brought about speedier drug development or faster market access. Instead, estimates of research costs that account for failed products and the cost of capital find average spending by pharmaceutical firms exceed \$1 trillion per approved drug [2].

Other key regulatory changes in recent years have included orphan drug incentives and accelerated assessment or even accelerated approvals. Orphan drug policies were designed to respond to constituencies with rare diseases who articulated concerns in the 1990s that market incentives were driving pharmaceutical firms toward 'lifestyle' diseases at the risk of ignoring difficult ailments. Extensions to patent life and other forms of market exclusivity are now commonplace for treatments that target diseases with a prevalence of 1 in 2,000 or less across a population. Similarly, both the U.S. Food and Drug Administration and the EMA offer accelerated review of medicines with public health benefits or targeting unmet needs. Drugs that are the first in their class or that will benefit large populations in underserved regions are granted faster regulatory analysis.

Together, the domestic and international regulatory initiatives undertaken over the past three decades reveal a complex dynamic between the regulatory environment and pharmaceutical innovation. Claims that regulators are holding back innovation seem overstated. At the same time, regulatory uncertainty in drug classes such as antibiotics and in some middle-income and developing countries has had a measurable effect on pharmaceutical firm behavior.

\section{Health care reform and competitiveness}

The 2010s are proving to be a decade of major health care system reform. Across the EU, health budgets are under unprecedented cost pressure and public sentiment has turned against free-market pricing for pharmaceuticals. In the United States, the Patient Protection and Affordable Care Act ("Obamacare") is expanding insurance coverage, but with little focus on managing the costs of care. The industry will pay additional taxes under the Act, but also will likely benefit from a larger market. In the middle-income nations of Brazil and China, health expenditures on pharmaceuticals have been rising at 10 to 20 percent annually, drawing significant industry attention and investments in new research facilities. Other countries, such as India, are building globally competitive generic industries, but offer few incentives to branded drug producers. Countries are adopting different policies concerning the critical dimensions of financial incentives, social and legal structures, and regulatory environments for innovation. It is our hope that the articles in this special issue will stimulate further analysis of these issues and contribute to productive recommendations for the pharmaceuticals policy arena. 


\section{References}

[1] B. Achilladelis, Innovation in the pharmaceutical industry, in: Pharmaceutical Innovation: Revolutionizing Human Health, R. Landau, B. Achilladelis and A. Scriabine, eds, Chemical Heritage Press, Philadelphia, 1999, pp. 1-147.

[2] J. DiMasi, R. Hansen and H. Grabowski, The Price of Innovation: New Estimates of Drug Development Costs, Journal of Health Economics 22 (2003), 151-185.

[3] J. Furman, K. Kyle, I. Cockburn and R. Henderson, Public and Private Spillovers, Location, and the Productivity of Pharmaceutical Research, NBER Working Paper 12509, 2006.

[4] J. Gole, S. Hegde and M. Vernon, Pharmaceutical R\&D Spending and Threats of Price Regulation, Journal of Financial and Quantitative Analysis 45 (2010), 239-264.

[5] R. Henderson and I. Cockburn, Scale, Scope and Spillovers: The Determinants of Research Productivity in Drug Discovery, RAND Journal of Economics 27 (1996), 32-59.

[6] K. Kaitin and J. DiMasi, Pharmaceutical Innovation in the 21st Century: New Drug Approvals in the First Decade, Clinical Pharmacology and Therapeutics 89 (2011), 183-188.

[7] M. Nusser and A. Tischendorf, The Research-basedPharmaceuticalIndustryas a Chance forthe Business Location Germany, Fraunhofer Gesellschaft, 2005.

[8] F. Pammolli, L. Magazzini and M. Riccaboni, The Productivity Crisis in Pharmaceutical R\&D, Nature Reviews Drug Discovery 10 (2011), 428-438.

[9] Pharmaceutical Research andManufacturersofAmerica, PharmaceuticalIndustry 2012 Profile.PhRMA, Washington, D.C., 2012. 